\title{
Interpersonal Personality Measures Show Circumplex Structure Based on New Psychometric Criteria
}

\author{
G. Scott Acton \\ Langley Porter Psychiatric Institute \\ University of California, San Francisco \\ William Revelle \\ Department of Psychology \\ Northwestern University
}

\begin{abstract}
The importance of the interpersonal circle in organizing the interpersonal domain is complemented by its empirical relations with broader personality taxonomies and with more specific personality variables. Yet circumplex structure in interpersonal measures has often been investigated using the "eyeball test" rather than using circumplex criteria of known effectiveness. Simulations (Acton, 1999) showed the effectiveness of 5 exploratory criteria ( 3 entirely new) that assess the properties of equal spacing, constant radius, and no preferred rotation. Along with Browne's (1992) criterion, these were applied to the Interpersonal Checklist (ICL; LaForge \& Suczek, 1955; $N$ = 763), Interpersonal Adjective Scales (IAS; Wiggins, 1979; $N \mathrm{~s}=$ 716 and 187), Revised IAS (IAS-R; Wiggins, Trapnell, \& Phillips, 1988; $N=474$ ), Inventory of Interpersonal Problems Circumplex Scales (IIP-C; Alden, Wiggins, \& Pincus, 1990; $N \mathrm{~s}=616$ and 1,381), and Inventory of Interpersonal Goals (IIG; Horowitz, Dryer, \& Krasnoperova, 1997; $N=318$ ). In corroboration of interpersonal theory, all showed circumplex structure.
\end{abstract}

Interpersonal theory is rooted in the assumption that everything people do in interaction with one another reflects an effort to achieve and maintain self-esteem and to avoid anxiety (Leary, 1957; Sullivan, 1953). People's characteristic ways of accomplishing these ends are called security operations (Sullivan, 1953) or interpersonal reflexes (Leary, 1957). These interpersonal reflexes are thought to be evident 
in any interpersonal situation, from enumerating in a psychiatric interview the things one finds hard to do to rating how accurately trait-descriptive adjectives on a personality test apply to oneself. In fact, a person's personality, according to interpersonal theory, comprises the set of all the person's interpersonal reflexes.

Interpersonal theory is a theory of the effects of interpersonal reflexes on dyadic interactions and on a person's general well-being (Kiesler, 1983) accompanied by a measurement theory of the interrelations of variables in the interpersonal domain. The circular taxonomy of variables known as the interpersonal circle comprises a two-dimensional array organized around the axes of dominance (vs. submission) and friendliness (vs. hostility; Freedman, Leary, Ossorio, \& Coffey, 1951). The measurement theory that has been applied to the interpersonal circle postulates that variables in the interpersonal domain are arranged into a circular array in two-dimensional space known as a circumplex (Guttman, 1954). Psychometric criteria exist to determine whether a given group of variables comprises a circumplex (e.g., Acton, 1999; Browne, 1992; Fisher, 1997; Upton \& Fingleton, 1989).

The theoretical ordering of variables into a circumplex comprises a nomological net (Gurtman, 1992a). One advantage of a circumplex representation of the interpersonal domain is that it provides an explicit structural model of the domain. A circumplex is an explicit integrative framework specifying the relations of variables to each other. Thus, the interpersonal circumplex is a particular kind of taxonomy of interpersonal variables. An alternative kind of taxonomy is a simple structure (Thurstone, 1947). According to one common interpretation, in a perfect simple structure variables have nonzero loadings on one and only one factor (Revelle \& Rocklin, 1979). Both circumplexes and simple structures are taxonomies of variables, not of people. Even as measured by a simple structure of variables, people could be normally distributed in two-dimensional space.

A circumplex representation allows the mapping of fuzzy concepts such as interpersonal terms. These terms can be considered labels for fuzzy sets, defined as classes without sharp boundaries in which there is a gradual but specifiable transition from membership to nonmembership (Horowitz \& Malle, 1993). This view is consistent with the view that fuzziness is a characteristic of natural language categories in general (Acton, 1998; Hersh \& Caramazza, 1976).

Two kinds of fuzziness can be distinguished: fuzziness in which a variable is an imperfect measure of one particular dimension (represented by the vector length of a variable or its communality on the two circumplex dimensions) and fuzziness in which a variable simultaneously measures more than one dimension (represented by the angular location of a variable). These two kinds of fuzziness can coexist, but whereas fuzziness in terms of imperfect communality can exist in either a circumplex or a simple structure, fuzziness in terms of angular location is a defining feature of a circumplex and an exclusionary feature of a simple structure.

The interpersonal circle is a valuable taxonomy of the interpersonal domain for two main reasons. First, the interpersonal circle is valuable because of its 
nomological relations with other interpersonal and noninterpersonal variables (e.g., Gurtman, 1992b; Hofstee, de Raad, \& Goldberg, 1992; McCrae \& Costa, 1989; Pincus, Gurtman, \& Ruiz, 1998; Saucier, 1992; Trapnell \& Wiggins, 1990; Whiteman, Bedford, Grant, Fowkes, \& Deary, 2001; Wiggins \& Broughton, 1991). Second, the interpersonal circle is valuable because of the heuristic value of its specific and testable assumptions concerning circumplex structure (e.g., Acton, 1999; Browne, 1992; Fisher, 1997; Upton \& Fingleton, 1989). These assumptions apply to any group of variables designed to represent the interpersonal domain, whether single-word descriptors or sentences, whether in English or otherwise (e.g., Blas \& Forzi, 1998; Rosén, 1992; Weinryb et al., 1996).

\section{INSTRUMENTS USED TO REPRESENT THE INTERPERSONAL CIRCLE}

Various instruments have been used to represent the interpersonal domain as a circumplex. Among them are the Interpersonal Checklist (ICL; LaForge \& Suczek, 1955), Interpersonal Adjective Scales (IAS; Wiggins, 1979), Revised Interpersonal Adjective Scales (IAS-R; Wiggins, Trapnell, \& Phillips, 1988), Inventory of Interpersonal Problems Circumplex Scales (IIP-C; Alden, Wiggins, \& Pincus, 1990), and Inventory of Interpersonal Goals (IIG; Horowitz, Dryer, \& Krasnoperova, 1997). The research described in the following tests these instruments for circumplex structure.

Most interpersonal instruments, including those investigated herein, are scored into eight scales called octants labeled counterclockwise with two letters of the alphabet. The benefit of using octant scales instead of 16th scales or individual items is that such aggregation increases each scale's internal consistency (alpha) reliability. The square root of reliability, in turn, places a cap or upper limit on a scale's validity.

ICL

The interpersonal circle was first operationalized by the ICL (LaForge \& Suczek, 1955). The ICL was devised as a means of operationalizing the interpersonal system of personality developed by the Kaiser Foundation research group in the 1950s (Freedman et al., 1951; LaForge \& Suczek, 1955) and summarized by Leary (1957). Although this elaborate system of personality included five levels of analysis (public communications, conscious description, private symbolizations, the unexpressed unconscious, and values), the primary use of the ICL has been as a selfreport instrument-hence as a measure of conscious description.

The circular format of the ICL was not originally tailored to meet the explicit assumptions of circumplex structure; only later was the relevance of Guttman's 
(1954) work recognized. Even within Guttman's framework, the format of the ICL might better be described as a radex than as a circumplex because of the inclusion within each octant of an intensity dimension running from the center to the periphery of the circle. Because this intensity dimension has not fared well empirically, however (Paddock \& Nowicki, 1986), most recent work (e.g., McCormick \& Goldberg, 1997) has ignored the intensity dimension, collapsing items within each octant into the same scale. Under these conditions, the hypothesized structure of the ICL is a circumplex.

Format. The ICL is a 128-item self-report instrument designed to measure interpersonal reflexes. Within each octant, items are designed to range from adaptive manifestations of a particular interpersonal reflex to extreme and maladaptive manifestations. Participants are asked to respond by filling in a blank if an item applies to them and leaving it blank if it does not. Example items from the Responsible-Overgenerous (NO) scale, in order of increasing extremity, are "helpful," "enjoys taking care of others," "generous to a fault," and "spoils people with kindness."

Validity. The validity of the ICL scales has been investigated in more than 300 studies (summarized by Taulbee \& Clark, 1982). Among these, Leary's early studies (e.g., Leary, 1957) remain noteworthy validations.

Circumplex structure. The ICL was found to have questionable circumplex structure by the method of visually inspecting the plots of the octant scales in twodimensional space (McCormick \& Kavanagh, 1981; Paddock \& Nowicki, 1986; Wiggins, 1979) — a necessarily subjective method that we refer to as the "eyeball test." Another method, based on latent correlations of octant scales, later indicated an acceptable degree of circumplexity (Wiggins, Steiger, \& Gaelick, 1981). By that time, however, interpersonal researchers had already begun to create newer and, it was hoped, better representations of the interpersonal circumplex.

\section{IAS}

The IAS (Wiggins, 1979) represents the next attempt to operationalize the interpersonal circumplex. The IAS is comprised of trait-descriptive adjectives based on a lexical approach to personality description. The IAS octant scales correspond to a facet analysis of cognitive categories of social perception (Foa \& Foa, 1974).

Format. The IAS is a 128-item self-report instrument designed to measure interpersonal traits. Items request that participants rate themselves using an 8-point response format ranging from 1 (very inaccurate) to 8 (very accurate) on trait-descriptive adjectives. Example items from the Gregarious-Extraverted (NO) scale are "cheerful" and "outgoing." 
Validity. The scales of the IAS have been shown to be related to a number of broader personality taxonomies, including the Five-factor model of personality (FFM; McCrae \& Costa, 1989) and the Psychoticism-Extraversion-Neuroticism model (Wiggins \& Broughton, 1985). The IAS has also been shown to be related to a number of more specific personality constructs, including narcissism (Buss \& Chiodo, 1991), interpersonal manipulation (Buss, Gomes, Higgins, \& Lauterbach, 1987), mate preferences (Buss \& Barnes, 1986), and nonverbal behavior (Gifford \& O'Connor, 1987). Indeed, Wiggins and Broughton (1991) determined the angular location of 172 personality scales with reference to the coordinates of the IAS.

Circumplex structure. The IAS was constructed explicitly to have circumplex structure through an iterative procedure described as "trial and error" (Wiggins, 1979, p. 397). The last step in this iterative procedure was the comparison of five sets of interpersonal item pools on an index of circumplex structure. A hypothetical factor matrix was constructed to represent a perfect circumplex solution for variables of the given level of reliability (as estimated from communalities). The sum of the absolute differences between elements in the hypothetical factor matrix and elements in the obtained factor matrix was taken as the index of circumplexity. Five sets of interpersonal item pools were compared on this index and the best one was retained as the final version of the IAS.

Beyond the iterative procedure used to construct the IAS, the only procedure used by Wiggins (1979) to evaluate its circumplex structure was the eyeball testthe correlation matrices were examined to see if they seemed to have the appropriate circumplex pattern. A more refined version of this method, based on latent rather than observed correlations (Wiggins et al., 1981), reaffirmed the conclusion that the IAS has circumplex structure. A later analysis using structural equations modeling found that the IAS forms only a quasi-circumplex-that is, the IAS fits a model in which all nonzero factor loadings are freed but subject to certain equality constraints (Gaines et al., 1997). This result has been disputed, however, based on the argument that the authors' use of structural equations modeling was inappropriate (Gurtman \& Pincus, 2000). Instead, Browne's (1992) criterion for circumplex structure was applied to show that the IAS has equal axes but unequal spacing of octants (Gurtman \& Pincus, 2000), although the unequal spacing produced differences from the equally spaced ideal that were of trivial practical significance for assessment purposes.

\section{IAS-R}

Because the IAS, comprised of 128 adjectives, is a long instrument, and because a new computer program was developed for creating circumplex scales, it was deemed desirable to create a foreshortened version of the IAS that, in addition, 
might have superior circumplex properties. Researchers therefore attempted to derive such an instrument using the original item pool of the IAS, resulting in the creation of the Revised IAS (IAS-R; Wiggins, Trapnell, \& Phillips, 1988).

Format. The IAS-R is a 64-item self-report instrument designed to measure interpersonal traits. Items request that participants rate themselves using an 8-point response format ranging from 1 (very inaccurate) to 8 (very accurate) on trait-descriptive adjectives. Example items from the Gregarious-Extraverted (NO) scale are "neighborly" and "enthusiastic."

Validity. Within all octant scales, the scales of the IAS-R have been shown to be related to characteristic interpersonal problems measured by the IIP-C (Wiggins, Phillips, \& Trapnell, 1989). Within certain octant scales, the scales of the IAS-R have also been shown to be related to the dimensions of psychopathology measured by the Psychological Screening Inventory: Alienation, Social Nonconformity, Discomfort, Expression, and Defensiveness (Wiggins et al., 1989).

The validity of the scales of the IAS-R has shown patterns of relations to other personality taxonomies and personality constructs similar to those shown by the IAS, with slight differences. For example, certain items in the IAS that tapped the Conscientiousness factor of the FFM were removed in the IAS-R (Wiggins et al., 1988), bringing the IAS-R more in line with the theory that Conscientiousness and the interpersonal circle are orthogonal.

Circumplex structure. Beyond the method used to construct the IAS-R, the only method used by its authors to evaluate its circumplex structure was the eyeball test. Even the more systematic method used on other questionnaires (Wiggins et al., 1981) apparently was not used on the IAS-R. Based on an approximation to the latter method using structural equations modeling, Gaines et al. (1997) argued that the IAS-R is best described as a quasi-circumplex. This conclusion was disputed by Gurtman and Pincus (2000), however, who argued that structural equation modeling is not uniquely state of the art for assessing circumplex structure and showed that the IAS-R has acceptable circumplex structure according to other more appropriate criteria.

\section{IIP-C}

The Inventory of Interpersonal Problems (IIP; Horowitz, Rosenberg, Baer, Ureño, \& Villaseñor, 1988) was developed from frequently reported interpersonal problems among outpatients in brief dynamic psychotherapy (Horowitz, 1979). The original scoring format for the IIP consists of a total score and six subscales (Hard to Be Assertive, Hard to Be Sociable, Hard to Be Submissive, Hard to Be Intimate, 
Too Responsible, and Too Controlling). Neither the method of item generation nor the original subscales of the IIP were tailored to meet the specific assumptions of the interpersonal circumplex. Nevertheless, because interpersonal problems fall squarely within the domain of interpersonal relationships, interpersonal theory predicts that interpersonal problems should have circumplex structure. To realize this prediction, researchers sampled items from the original IIP to create the IIP-C (Alden, Wiggins, \& Pincus, 1990).

Format. The IIP-C is a 64-item self-report instrument designed to measure interpersonal deficiencies and excesses. Items request that participants rate themselves using a 5-point response format ranging from 0 (not at all) to 4 (extremely) on phrases beginning "It is hard for me to ..." or "I am too ...." Example items from the Intrusive (NO) scale are "It is hard for me to stay out of other people's business," and "I want to be noticed too much."

Validity. External validity of the IIP-C scales has been demonstrated by its ability to predict and to be predicted by process and outcome of psychotherapy (e.g., Davies-Osterkamp, Strauss, \& Schmitz, 1996; Gurtman, 1996; Horowitz, Rosenberg, \& Bartholomew, 1993; Maling, Gurtman, \& Howard, 1995; Muran, Segal, Samstag, \& Crawford, 1994). The relation of the IIP-C to the FFM (Gurtman, 1995) and to adult attachment styles (Bartholomew \& Horowitz, 1991; Horowitz et al., 1993) has also been demonstrated.

Circumplex structure. In analyses on an undergraduate sample, two principal components were identified in the IIP corresponding to the interpersonal dimensions of Dominance and Friendliness, and eight 8-item scales were culled from the original 127 items, which, by the method of inspecting the correlation matrix and the resultant scatterplot of variables — that is, the eyeball test—were judged to be equally spaced in two dimensions and to meet the statistical criteria for a circumplex ordering (Alden et al., 1990). The resulting scales each tapped a different octant of the two-dimensional space. Structural validity of the IIP-C was demonstrated using confirmatory factor analysis to show that the IIP-C retains circumplex structure across levels of the general factor (i.e., general complaints; Tracey, Rounds, \& Gurtman, 1996). In addition, Browne's (1992) criterion, when applied to the IIP-C, indicated a good fit to a model with equal axes and equal spacing of octants (Pincus et al., 1998).

IIG

The IIG (Horowitz, Dryer, \& Krasnoperova, 1997) is designed to assess persons' goals in interpersonal relationships. Items spanning the interpersonal domain were identified in other personality instruments and were considered acceptable mea- 
sures of goals only if they were frequently endorsed in pilot studies and clearly and unambiguously described just one major goal.

Format. The IIG is a 32-item self-report instrument designed to measure interpersonal desires or wishes. Items request that participants rate themselves using a 5-point response format ranging from 0 (no, definitely not) to 4 (yes, definitely) on phrases beginning "When I am working on a task with someone, it is important to me to ...." Example items from the Friendly Dominant Goals (NO) scale are " ... let the other person know what I want," and " ... confront the other person with problems that come up."

Validity. Interpersonal goals are important because an interaction in which the behavior of one partner complements the goals of the other produces the most relationship satisfaction (Dryer \& Horowitz, 1997). Conversely, when a person's interpersonal goals fail to be realized across many relationships, that condition is called an interpersonal problem (Horowitz et al., 1997).

Circumplex structure. The authors of the IIG followed the procedures used by other investigators to generate a circumplex (Horowitz et al., 1997). The familiar procedure used was the eyeball test-items were plotted in two-dimensional space, and the best representatives of each octant (as indicated by communalities) were retained as the final version of the IIG.

\section{CIRCUMPLEX STRUCTURE}

Although most of the included instruments have been tested using circumplex criteria of unknown effectiveness (e.g., the eyeball test), the novelty of this study is the use of criteria of demonstrated effectiveness, some entirely new. Monte Carlo simulations (Acton, 1999) showed all of the exploratory criteria discussed in the following to be sensitive to various aspects of circumplex structure. The simulations involved the generation of numerous data sets with known properties that were systematically varied: actual structure (circumplex vs. simple), deviation from circularity (equal vs. unequal axes), type of scoring (raw vs. deviation scored), rotation (unrotated vs. varimax rotated), size of general factor (none vs. large vs. variable), number of participants (150 vs. 600), and number of variables (64 vs. 128). ${ }^{1}$ Whereas some existing criteria were shown to be ineffective or fallacious, the exploratory criteria discussed in the following were all shown to be effective. Thus,

\footnotetext{
${ }^{1}$ Because the Gap Test (a measure of equal spacing based on Upton \& Fingleton, 1989) was especially sensitive to number of variables, a further simulation was conducted on the Gap Test using a wider range in number of variables $(8,16,32,64$, and 128).
} 
they are used hereafter to assess the circumplex properties of data in the interpersonal domain. The five effective exploratory criteria are described using equations with the following notation: $f$ denotes factors, $n f$ denotes number of factors, $v$ denotes variables, $n v$ denotes number of variables, $\theta$ denotes angles of rotation, $R$ denotes Minkowski R (a generalization of the Euclidean method of finding the distance between two points), and $\lambda$ denotes factor loadings.

\section{Fisher Test}

In a perfect circumplex, variables should be equidistant from the center of the circle - that is, the circle should have a constant radius. The Fisher Test (Fisher, 1997) is a measure of constant radius. The basic idea is that there should be minimal variability in the distance of variables from the center of the circle. In the Fisher Test (as well as three other criteria presented hereafter), the index of variability is the coefficient of variation - that is, the standard deviation divided by the mean. A small value of the Fisher Test would indicate equal axes (such as would be found in a circle), whereas a large value would indicate unequal axes (such as would be found in an ellipse). The equation for the Fisher Test is

$$
\text { Fisher Test }=\frac{\sigma_{X_{v}}}{\bar{X}_{v}} \text {, where } X_{v}=\sum_{f=1}^{n f} \lambda_{f_{v}}^{2} \text {. }
$$

\section{Gap Test}

In a perfect circumplex, variables should be equally spaced around the circumference of the circle. The Gap Test (based on Upton \& Fingleton, 1989) is a measure of equal spacing. The basic idea is that the gap from one variable to its neighbor on one side should be equal to the gap from any other variable to its neighbor in the same direction. Although perfect equality of gaps is an ideal not to be expected in real data, it is still possible to expect a close approximation to this ideal, which can be expressed as a small variance in the gaps. A small value of the Gap Test would indicate a circumplex, whereas a large value would indicate a simple structure. The equation for the Gap Test is

$$
\begin{aligned}
\text { Gap Test }= & \sigma_{X v}^{2}, \text { where } X_{v}=\left(\theta_{v+1}-\theta_{v}\right) \text { for } v=1 \text { to }(n v-1), \\
& \text { and } X_{v}=\left(2 \pi+\theta_{1}-\theta_{n v}\right) \text { for } v=n v .
\end{aligned}
$$




\section{RT}

In a perfect circumplex, rotation should make no difference-not in terms of variance accounted for, which is unaffected by rotation, but in terms of the fit of a rotation criterion like varimax, quartimax, and so on. The Rotation Test (RT; Acton, 1999 ) is a new circumplex criterion that measures the degree to which all rotations are equally good - that is, of no preferred rotation. The basic idea of RT is that a varimax-like criterion should not change as a function of angle of rotation. This expectation is based on the fact that varimax is designed to index simple structure, and in a circumplex, simple structure is lacking. $R T$ is defined, for each angle, as the sum across variables of the variance across factors of the squared loadings. A small value of RT would indicate a circumplex, whereas a large value would indicate a simple structure. The equation for RT is

$$
\mathrm{RT}=\frac{\sigma_{X_{\theta}}}{\bar{X}_{\theta}} \text {, where } X_{\theta}=\sum_{v=1}^{n v} \sigma_{v \theta}^{2} \text {, and } \sigma_{v \theta}^{2}=\frac{\sum_{f=1}^{n f}\left(\lambda_{f v \theta}^{2}-\bar{\lambda}_{v \theta}^{2}\right)^{2}}{n f-1} \text {. }
$$

\section{MT}

Like RT, the Minkowski Test (MT; Acton, 1999) is a new circumplex criterion that measures no preferred rotation. MT incorporates a Minkowski R, which is a generalization of the Euclidean method of finding the distance between two points. A Minkowski $\mathrm{R}$ of 1 is the equivalent of a city block metric; to go two city blocks north and two west in a city block metric is four blocks, rather than the $2 * \operatorname{sqrt}(2)$ blocks that a crow would fly. A Minkowski R of 2 is a standard Euclidean space in which the distance from one point to the next is equal to the square root of the sum of squares. A Minkowski R greater than 2 is best thought of as a generalization of Euclidean space in which the distance from one point to the next is equal to the $R$ th root of the sum of the $R$ th powers. MT is calculated by first finding the sum across factors of the loading raised to the $R$ th power and second by finding the sum across variables of the previous sum raised to the $2 / R$ th power. A small value of MT would indicate a circumplex, whereas a large value would indicate a simple structure. The equation for MT is

$$
\text { MT }=\frac{\sigma_{X_{\theta}}}{\bar{X}_{\theta}} \text {, where } X_{\theta}=\sum_{v=1}^{n v}\left(\sum_{f=1}^{n f} \lambda \lambda_{f v}^{R}\right)^{2 / R} \text {. }
$$


VT

The Variance Test (VT; Acton, 1999) ${ }^{2}$ is yet another new circumplex criterion that measures no preferred rotation. In a circumplex there should be minimal variability across angles in the variance across variables of the squared loading on the first factor divided by the communality. A small value of VT would indicate a circumplex, whereas a large value would indicate a simple structure. The equation for VT is

$$
\mathrm{VT}=\frac{\sigma_{X_{\theta}}}{\bar{X}_{\theta}} \text {, where } X_{\theta}=\sigma_{Y_{v \theta}}^{2} \text {, and } Y_{v \theta}=\frac{\lambda_{1 v \theta}^{2}}{\sum_{f=1}^{n f} \lambda_{f v \theta}^{2}}
$$

\section{Browne's Criterion}

All of the criteria presented above are exploratory in nature. Browne (1992) presented an alternative criterion for circumplex structure, along with a program called CIRCUM for computing model fit using this criterion. To compare results from the exploratory methods with Browne's method, we fit an $m=3$ version of Browne's Fourier model to each raw-scored correlation matrix. (Deviation scoring was not used in these analyses.) We began by constraining the model to equal communality (i.e., constant radius) and equal spacing, then relaxed one constraint, then the other, then both. The indexes used to assess model fit were (a) the maximum-likelihood discrepancy function, (b) the chi-square likelihood ratio, (c) the root mean square error of approximation (RMSEA; Brown \& Cudeck, 1992), (d) the goodness-of-fit index (GFI; Jöreskog \& Sörbom, 1986), and (e) the adjusted GFI (AGFI; Jöreskog \& Sörbom, 1986; Maiti \& Mukherjee, 1990). Unlike the other measures of model fit, RMSEA and AGFI are parsimony-weighted indexes, which therefore take into account model complexity (i.e., the number of parameters estimated). Browne and Cudeck (1992, p. 239) suggested that RMSEA values less than .08 indicate a reasonable fit, whereas typical practice (e.g., Schumacker \& Lomax, 1996, p. 121) is to interpret GFI and AGFI values greater than .90 as a good fit.

\footnotetext{
${ }^{2}$ Elsewhere (Acton, 1999) the Variance Test (VT) is referred to as VT2. The omission of VT1 due to insufficient power, however, justifies the simplified notation.
} 


\section{HYPOTHESES}

A key idea of interpersonal theory is that any instrument designed to assess the breadth of the interpersonal domain should have circumplex structure. Because the five instruments included were explicitly developed to represent the interpersonal circle, we hypothesize that they should have constant radius, equal spacing, and no preferred rotation.

\section{METHOD}

\section{Procedure}

After signing forms giving informed consent, participants completed one or more questionnaires, including those discussed in this study. The University of Oregon students completed the adjectives in the IAS as part of a longer list of 1,710 trait-descriptive adjectives, from which data on the IAS items were later removed.

\section{Participants}

The widowed or divorced sample (who completed the ICL) was made up primarily of middle-aged adults (the median age was 41 years) with about half of each gender. The college student samples were made up primarily of young adults with about half of each gender. The college students were taking introductory psychology courses and participating for course credit.

In the Northwestern University samples, the number of participants reported reflects the number remaining after those with more than $2 \%$ missing values were removed (the remaining missing values were replaced with the mean of the item). In the other samples, there were no missing values.

ICL Sample. Participants were 763 middle class adults at a Chicago convention for widowed or divorced persons. ${ }^{3}$

IAS Sample 1. Participants were 716 Northwestern University students.

IAS Sample 2. Participants were 187 University of Oregon students. ${ }^{4}$

\footnotetext{
${ }^{3}$ We thank Clarence C. McCormick for making these data available. McCormick and Goldberg (1997) reported previous analyses of these data.

${ }^{4}$ We thank Lewis R. Goldberg for making these data available. Goldberg (1982) and Wiggins (1979) reported previous analyses of these data.
} 
IAS-R Sample. Participants were 474 University of Wisconsin-Parkside students. ${ }^{5}$

IIP-C Sample 1. Participants were 616 Northwestern University students.

IIP-C Sample 2. Participants were 1,381 University of Wisconsin-Parkside students. ${ }^{6}$

IIG Sample. Participants were 318 Northwestern University students.

\section{Analyses}

Five of the leading instruments representing the interpersonal circle were administered to multiple samples of adults. For analyses using the five new exploratory criteria, the resulting data were deviation scored-that is, the participant's mean across all items was subtracted from the response to each item ${ }^{7}$ - to improve their circumplex properties (Acton, 1999). For analyses using Browne's (1992) criterion, however, raw-scored data were used. The items in each instrument were scored into octant scales (Table 1), based on which means, standard deviations, internal-consistency (alpha) reliabilities, correlation matrices, and factor matrices were generated. The five exploratory circumplex criteria discussed above were then computed for each instrument using as input the unrotated factor matrix. If the value of the Fisher Test on the first pair of factors was lower than the critical value in Table 2 (using $\alpha=.05$ ), then the null hypothesis of unequal axes was rejected and the instrument was said to have equal axes. If the value of the Gap Test, RT, MT, or VT was lower than the corresponding critical value in Table 2 (using $\alpha=.05$ ), then the null hypothesis of simple structure was rejected and the instrument was said to form a circumplex.

${ }^{5}$ We thank Michael B. Gurtman for making these data available.

${ }^{6}$ We thank Michael B. Gurtman for making these data available. Gurtman (1995), Haslam and Gurtman (1999), and Tracey et al. (1996) reported previous analyses of 1,093 of these cases. Gurtman (1992b, 1993) reported previous analyses of a much smaller subset. Gurtman and Balakrishnan (1998) reported previous analyses of 1,981 cases, including this sample.

${ }^{7}$ Deviation scoring is often called ipsatizing, but this latter term is ambiguous because it could mean either deviation scoring or $z$ scoring. Deviation scoring within each participant (as used herein) should also be distinguished from deviation scoring within each variable (not used). The effect of deviation scoring differs from that of $z$ scoring in that deviation scoring does not correct for extreme values, whereas $z$ scoring does. To the extent that there are few extreme values, the two procedures should have similar effects. 


\section{RESULTS}

Normative data on the octant scales of each instrument are reported (Table 1). Plots of the octant scale factor loading rotated using Procrustes rotation to minimize the overall discrepancy between observed and ideal locations are also illustrated (Figures 1, 2, 3, and 4), although unrotated factor loadings were used for calculating the exploratory circumplex criteria. Because the clearest implication of a simulation study (Acton, 1999) was that deviation scoring is beneficial for most interpretations of the included exploratory criteria, all results using the exploratory criteria on the interpersonal data were based on deviation scored data. In addition, all results using these criteria were based on the first pair of unrotated factors. Except where otherwise noted, all of the reported exploratory criterion values are statistically significant at $p<.05$ (see Table 2). Results using Browne's (1992) circumplex criterion are also reported (Table 3 ).

\section{ICL Sample}

The ICL was an equal-axes circle-that is, it showed constant (equal) radius $($ Fisher $=.07)$. Although it did not exhibit the circumplex property of equally spaced octants (Gap Test $=.32, n s)$, the fact that it showed no preferred rotation (RT $=.18 ; \mathrm{MT}=.08 ; \mathrm{VT}=.36)$ indicated that it had circumplex structure. According to Browne's (1992) criterion, the ICL had constant radius but unequally spaced octants $(\mathrm{RMSEA}=.079 ; \mathrm{GFI}=.970 ; \mathrm{AGFI}=.936)$, which agreed perfectly with the exploratory criteria.

\section{IAS Sample 1}

The exploratory criteria indicated that the IAS had constant radius (Fisher $=.04$ ) with circumplex structure. In particular, it showed the circumplex properties of equally spaced octants (Gap Test $=.06)$ and no preferred rotation $(\mathrm{RT}=.05 ; \mathrm{MT}=$ .03 ; VT = .15). Browne's (1992) criterion, however, indicated a better fit for a model with constant radius but unequally spaced octants $(\mathrm{GFI}=.949)$.

\section{IAS Sample 2}

Again in this sample, the IAS was found by the exploratory criteria to have constant radius (Fisher $=.06$ ) with the circumplex properties of equal spacing of octants $($ Gap Test $=.01)$ and no preferred rotation $(\mathrm{RT}=.04 ; \mathrm{MT}=.04$; VT $=.22)$. With regard to Browne's (1992) criterion, a case could be made for constant radius and equal spacing $(\mathrm{GFI}=.896)$, but a better fit was obtained with unequal radius and equal spacing $(\mathrm{RMSEA}=.081 ; \mathrm{GFI}=.955 ; \mathrm{AGFI}=.905)$. 
TABLE 1

Normative Data on Octant Scales of Interpersonal Instruments

\begin{tabular}{|c|c|c|c|c|c|c|c|}
\hline \multirow[b]{2}{*}{ Octant } & \multirow[b]{2}{*}{ Octant Label } & \multicolumn{3}{|c|}{ Sample 1} & \multicolumn{3}{|c|}{ Sample 2} \\
\hline & & $M$ & $S D$ & $\alpha$ & $M$ & $S D$ & $\alpha$ \\
\hline \multicolumn{8}{|c|}{ Interpersonal Checklist } \\
\hline PA & Managerial-Autocratic & -0.25 & 2.35 & 0.62 & & & \\
\hline $\mathrm{BC}$ & Competitive-Exploitive & -0.08 & 2.23 & 0.61 & & & \\
\hline $\mathrm{DE}$ & Blunt-Aggressive & -0.41 & 2.11 & 0.51 & & & \\
\hline FG & Skeptical-Distrustful & -1.32 & 2.40 & 0.62 & & & \\
\hline $\mathrm{HI}$ & Modest-Self-Effacing & -0.66 & 2.38 & 0.62 & & & \\
\hline JK & Docile-Dependent & -0.07 & 2.11 & 0.48 & & & \\
\hline LM & Cooperative-Overconventional & 1.24 & 2.25 & 0.60 & & & \\
\hline NO & Responsible-Overgenerous & 1.55 & 2.46 & 0.64 & & & \\
\hline \multicolumn{8}{|c|}{ Interpersonal Adjective Scales } \\
\hline PA & Ambitious-Dominant & 14.65 & 13.18 & 0.82 & 14.11 & 12.59 & 0.78 \\
\hline $\mathrm{BC}$ & Arrogant-Calculating & -12.42 & 14.75 & 0.86 & -14.68 & 14.70 & 0.82 \\
\hline $\mathrm{DE}$ & Cold-Quarrelsome & -31.25 & 14.43 & 0.91 & -33.64 & 12.25 & 0.86 \\
\hline FG & Aloof-Introverted & -13.43 & 17.03 & 0.90 & -15.68 & 16.76 & 0.88 \\
\hline HI & Lazy-Submissive & -10.93 & 12.82 & 0.78 & -12.85 & 13.46 & 0.75 \\
\hline JK & Unassuming-Ingenuous & 1.40 & 13.13 & 0.78 & 0.67 & 14.22 & 0.74 \\
\hline LM & Warm-Agreeable & 29.02 & 14.41 & 0.92 & 34.63 & 12.65 & 0.89 \\
\hline NO & Gregarious-Extraverted & 24.14 & 15.63 & 0.91 & 27.46 & 14.35 & 0.89 \\
\hline \multicolumn{8}{|c|}{ Revised Interpersonal Adjective Scales } \\
\hline PA & Assured-Dominant & 2.70 & 3.79 & 0.77 & & & \\
\hline $\mathrm{BC}$ & Arrogant-Calculating & -1.47 & 3.97 & 0.71 & & & \\
\hline $\mathrm{DE}$ & Cold-Hearted & -6.41 & 3.93 & 0.73 & & & \\
\hline FG & Aloof-Introverted & -4.92 & 3.87 & 0.73 & & & \\
\hline HI & Unassured-Submissive & -2.06 & 4.16 & 0.73 & & & \\
\hline JK & Unassuming-Ingenuous & -1.48 & 3.52 & 0.59 & & & \\
\hline LM & Warm-Agreeable & 6.96 & 3.59 & 0.81 & & & \\
\hline NO & Gregarious-Extraverted & 4.63 & 3.66 & 0.73 & & & \\
\hline \multicolumn{8}{|c|}{ Inventory of Interpersonal Problems Circumplex Scales } \\
\hline $\mathrm{PA}$ & Domineering & -2.27 & 4.38 & 0.69 & -2.58 & 4.23 & 0.66 \\
\hline $\mathrm{BC}$ & Vindictive & -2.49 & 4.12 & 0.68 & -2.02 & 3.74 & 0.56 \\
\hline $\mathrm{DE}$ & Cold & -2.16 & 4.20 & 0.67 & -2.56 & 3.89 & 0.59 \\
\hline FG & Socially Avoidant & 0.35 & 4.66 & 0.71 & 1.15 & 4.59 & 0.67 \\
\hline $\mathrm{HI}$ & Nonassertive & 1.59 & 4.53 & 0.72 & 1.85 & 4.39 & 0.64 \\
\hline $\mathrm{JK}$ & Exploitable & 2.20 & 4.33 & 0.63 & 1.71 & 4.21 & 0.56 \\
\hline LM & Overly Nurturant & 2.80 & 4.45 & 0.65 & 2.53 & 4.20 & 0.55 \\
\hline NO & Intrusive & 0.10 & 4.39 & 0.61 & -0.33 & 4.31 & 0.53 \\
\hline
\end{tabular}


TABLE 1 (Continued)

\begin{tabular}{|c|c|c|c|c|c|c|c|}
\hline \multirow[b]{2}{*}{ Octant } & \multirow[b]{2}{*}{ Octant Label } & \multicolumn{3}{|c|}{ Sample 1} & \multicolumn{3}{|c|}{ Sample 2} \\
\hline & & $M$ & $S D$ & $\alpha$ & $M$ & $S D$ & $\alpha$ \\
\hline \multicolumn{8}{|c|}{ Inventory of Interpersonal Goals } \\
\hline PA & Dominant Goals & 2.69 & 1.85 & 0.64 & & & \\
\hline $\mathrm{BC}$ & Hostile-Dominant Goals & -1.03 & 2.02 & 0.24 & & & \\
\hline $\mathrm{DE}$ & Hostile Goals & -1.89 & 2.11 & 0.32 & & & \\
\hline FG & Hostile-Submissive Goals & -2.20 & 2.39 & 0.55 & & & \\
\hline $\mathrm{HI}$ & Submissive Goals & -0.11 & 2.38 & 0.64 & & & \\
\hline JK & Friendly-Submissive Goals & -0.91 & 2.01 & 0.30 & & & \\
\hline $\mathrm{LM}$ & Friendly Goals & 1.69 & 1.79 & 0.33 & & & \\
\hline NO & Friendly-Dominant Goals & 1.76 & 1.89 & 0.57 & & & \\
\hline
\end{tabular}

Note. Octants $=$ eight scales labeled counterclockwise with two letters of the alphabet.

TABLE 2

Critical Values and Power for Use of Circumplex Criteria to Reject Unequal Axes in Favor of Equal Axes, or to Reject Simple Structure in Favor of Circumplex Structure

\begin{tabular}{|c|c|c|c|c|c|c|c|c|}
\hline \multirow{3}{*}{$\begin{array}{l}\text { Circumplex } \\
\text { Criterion }\end{array}$} & \multicolumn{4}{|c|}{ Raw Scored Data $\alpha$ Level } & \multicolumn{4}{|c|}{ Deviation Scored Data $\alpha$ Level } \\
\hline & \multicolumn{2}{|c|}{.01} & \multicolumn{2}{|c|}{.05} & \multicolumn{2}{|c|}{.01} & \multicolumn{2}{|c|}{.05} \\
\hline & Critical & Power & Critical & Power & Critical & Power & Critical & Power \\
\hline \multicolumn{9}{|c|}{ Equal versus unequal axes } \\
\hline Fisher Test & .09 & .30 & .10 & .34 & .11 & .56 & .11 & 0.60 \\
\hline \multicolumn{9}{|c|}{ Circumplex versus simple structure } \\
\hline Gap Test & .29 & .30 & .30 & .31 & .13 & .48 & .14 & 0.50 \\
\hline RT & .04 & 19 & .06 & .31 & .11 & .95 & .19 & 1.00 \\
\hline MT & .02 & .29 & .04 & .43 & .06 & .97 & .09 & 1.00 \\
\hline VT & .23 & .31 & .28 & .32 & .37 & .90 & .47 & 0.98 \\
\hline
\end{tabular}

Note. Values listed for Gap Test apply only to measures with eight variables (e.g., octant scales). Adapted from Acton (1999). RT = Rotation Test; MT = Minkowski Test; VT = Variance Test.

\section{IAS-R Sample}

Like its predecessor the IAS, the IAS-R seemed to have, according to the exploratory criteria, all of the desirable properties of a constant radius measure (Fisher $=$ $.05)$ with equally spaced octants (Gap Test $=.07)$ and no preferred rotation $(\mathrm{RT}=$ $.08 ; \mathrm{MT}=.05 ; \mathrm{VT}=.21$ ). Browne's (1992) criterion, however, indicated a better fit for constant radius but unequal spacing $(\mathrm{GFI}=.947)$. 

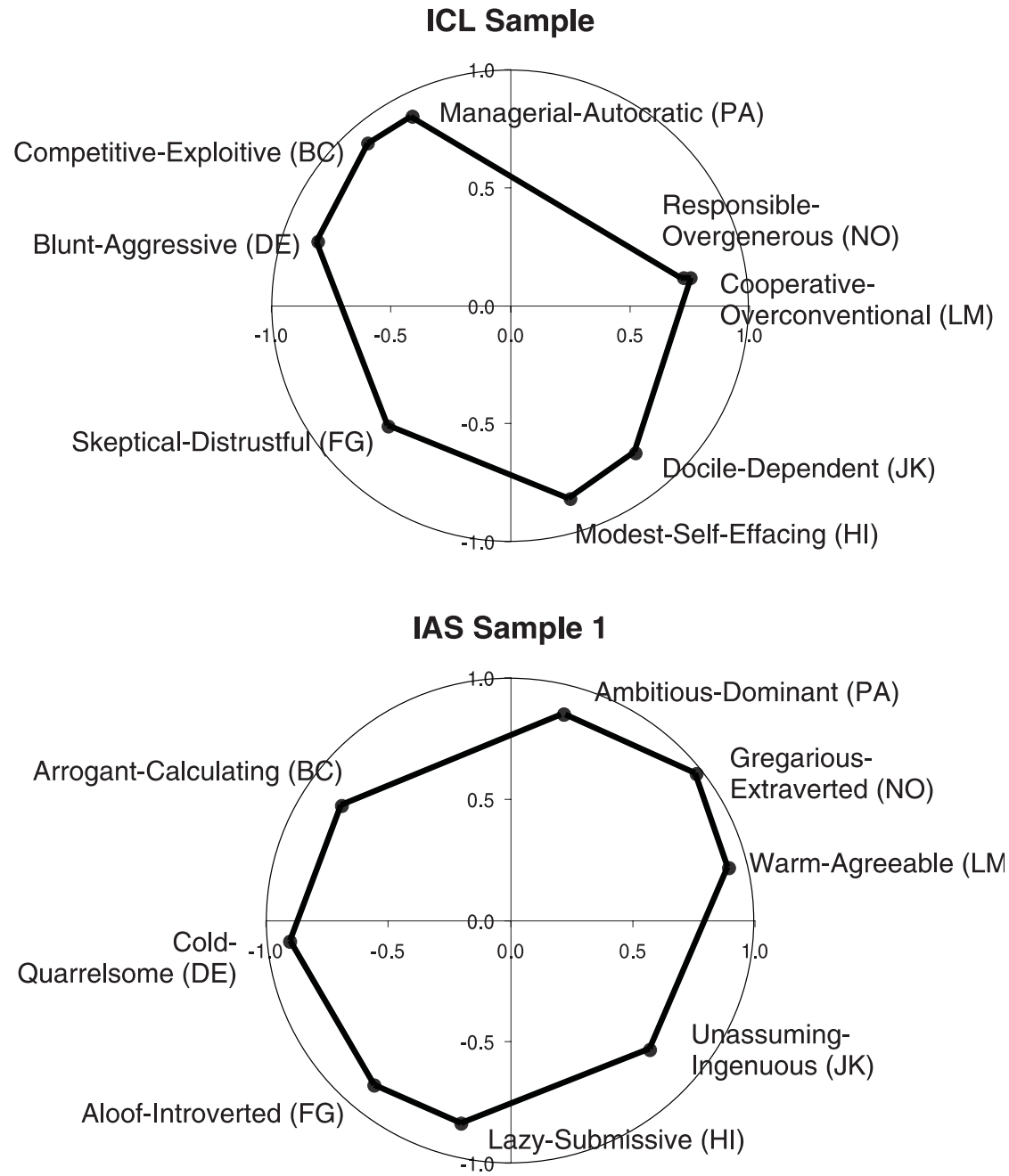

FIGURE 1 Plots of rotated factor loadings for the Interpersonal Checklist (ICL) Sample and the Interpersonal Adjective Scales (IAS) Sample 1.

\section{IIP-C Sample 1}

The exploratory IIP-C results indicated that this instrument is an outstanding example of a circumplex. The IIP-C had equal radius (Fisher $=.04$ ), showed equally spaced octants $(\mathrm{Gap}$ Test $=.04)$, and favored all rotations equally $(\mathrm{RT}=.07 ; \mathrm{MT}=$ 


\section{IAS Sample 2}

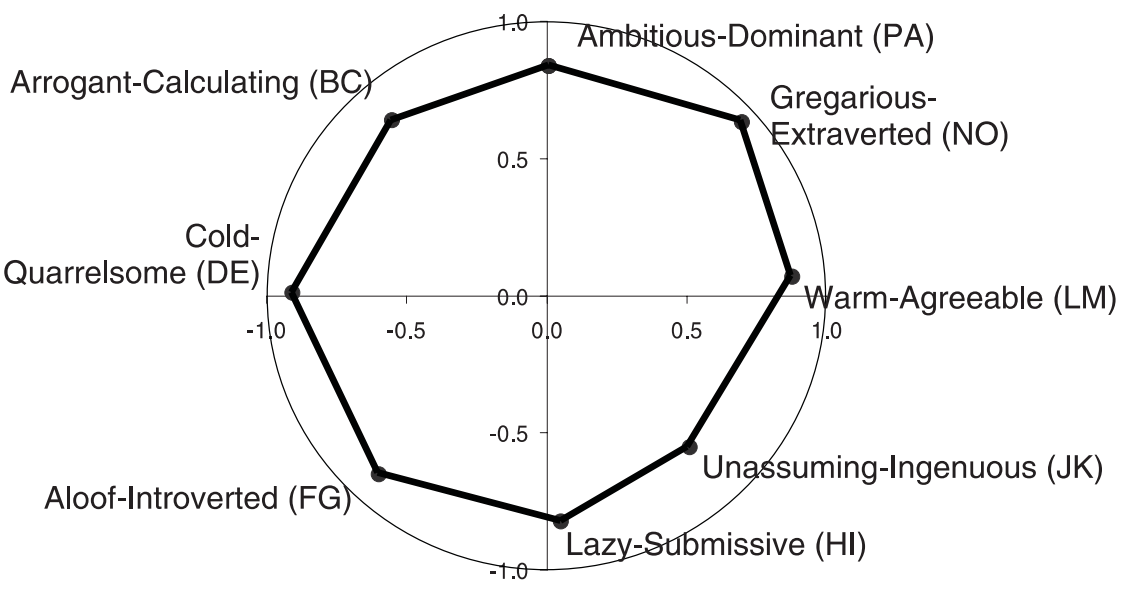

IAS-R Sample

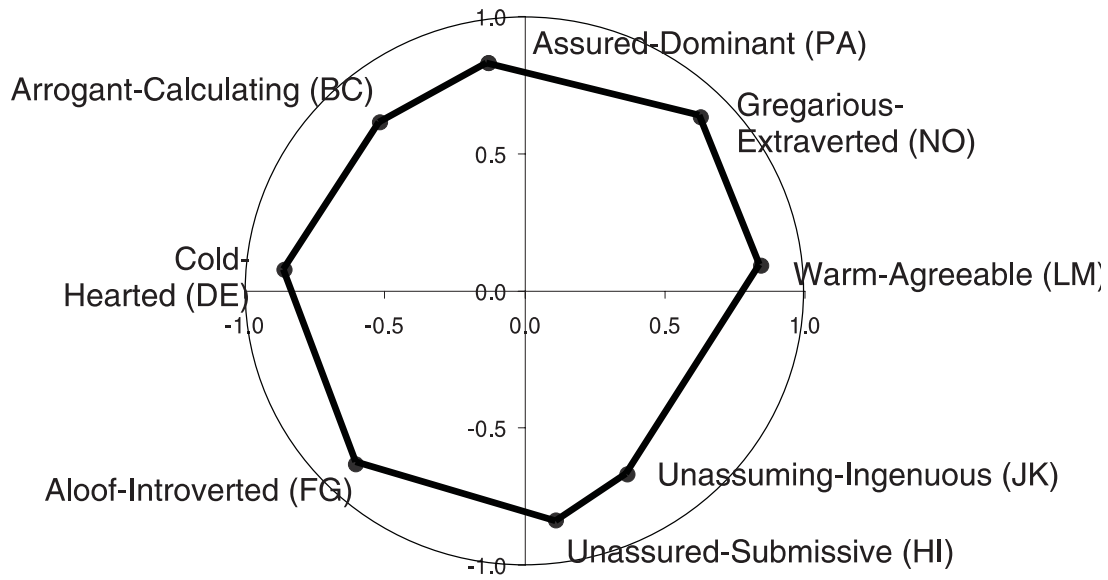

FIGURE 2 Plots of rotated factor loadings for the Interpersonal Adjective Scales (IAS) Sample 2 and the Revised IAS Sample. 


\section{IIP-C Sample 1}

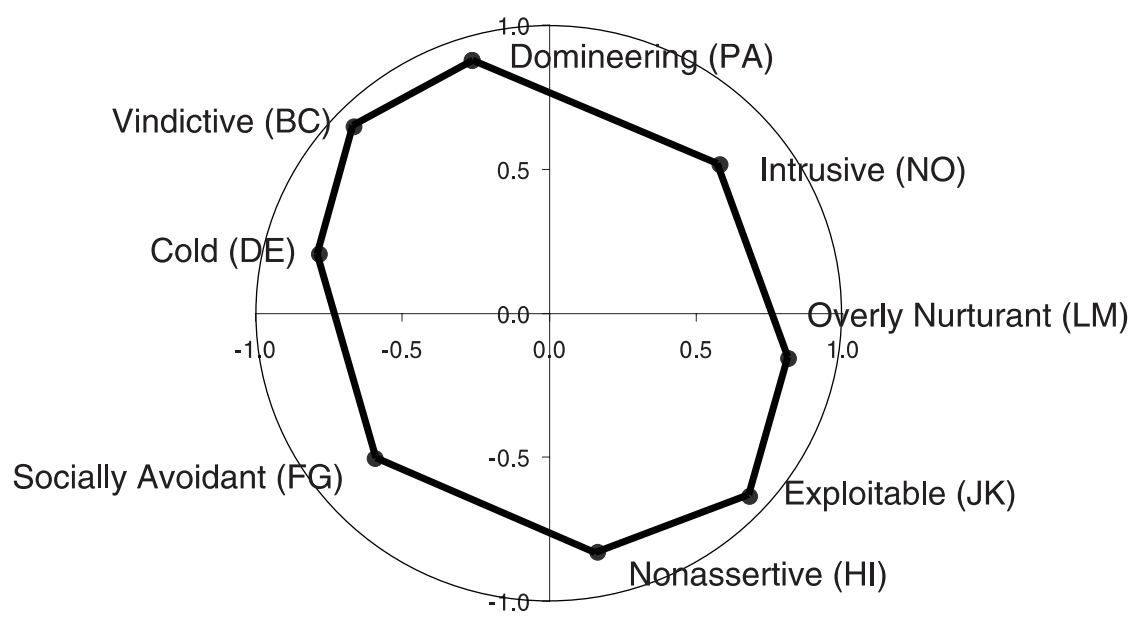

\section{IIP-C Sample 2}

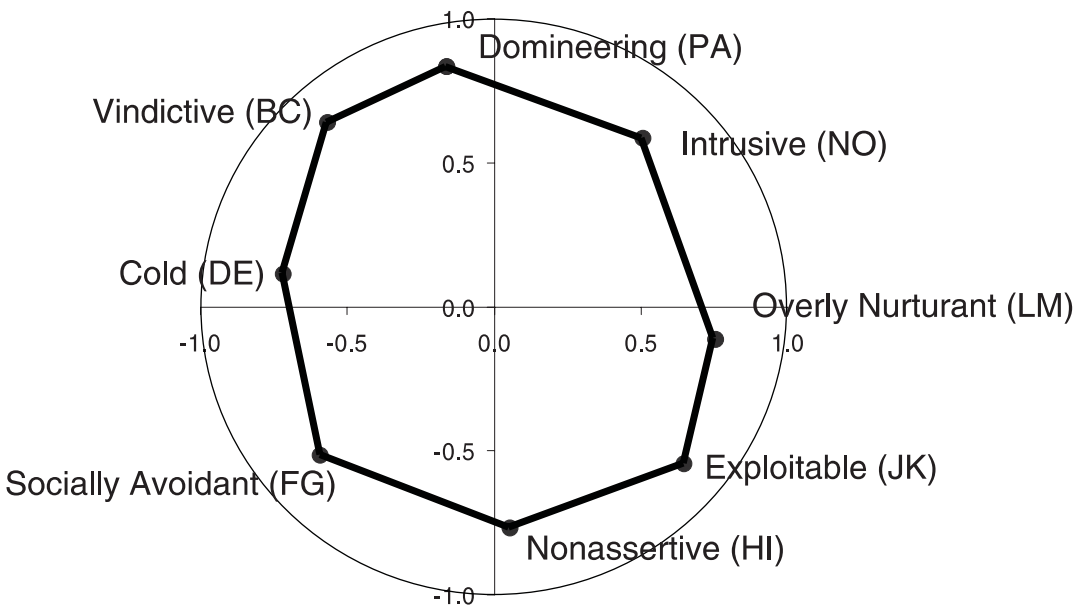

FIGURE 3 Plots of rotated factor loadings for the Inventory of Interpersonal Problems Circumplex Scales (IIP-C) Sample 1 and IIP-C Sample 2. 


\section{IIG Sample}

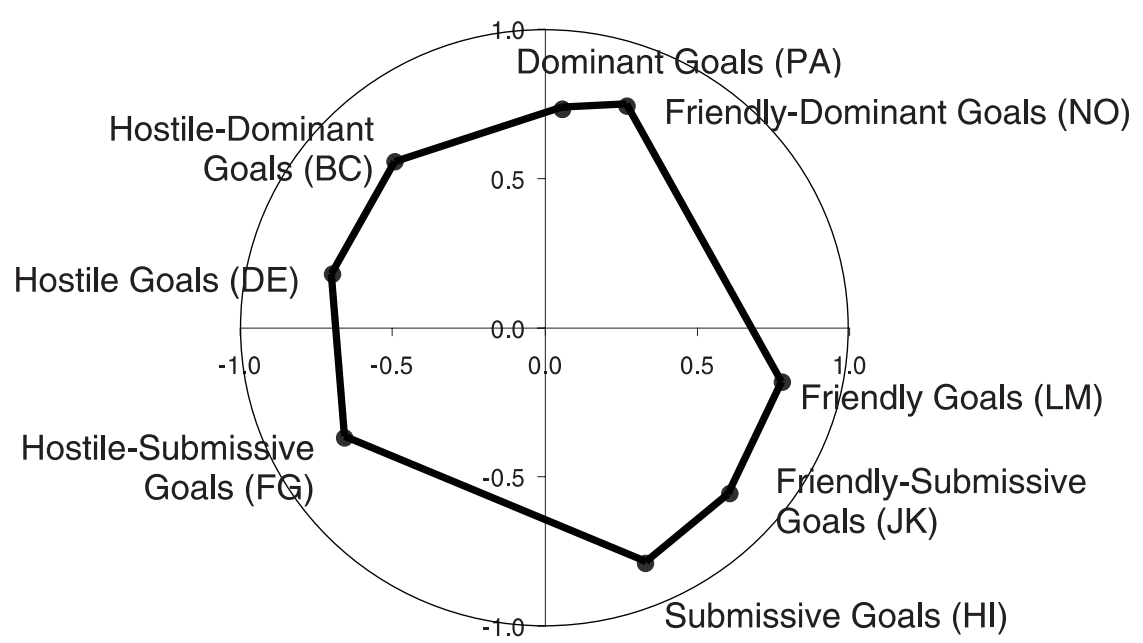

FIGURE 4 Plots of rotated factor loadings for the Inventory of Interpersonal Goals (IIG) Sample.

$.04 ; \mathrm{VT}=.28)$. According to Browne's (1992) criterion, a model with equal axes and equally spaced octants showed an adequate fit $(\mathrm{GFI}=.923)$.

\section{IIP-C Sample 2}

Replicating the previous IIP-C results, the exploratory criteria indicated that this instrument showed constant radius (Fisher $=.07$ ), equally spaced octants (Gap Test $=.02)$, and equal preference for all rotations $(\mathrm{RT}=.06 ; \mathrm{MT}=.03 ; \mathrm{VT}=.16)$. Browne's (1992) criterion indicated that the IIP-C had both constant radius and equally spaced octants $(\mathrm{GFI}=.945 ; \mathrm{AGFI}=.917)$.

\section{IIG Sample}

The IIG is a new instrument that showed most of the desirable circumplex properties. It had constant radius (Fisher $=.09)$ but unequally spaced octants (Gap Test $=$ $.16, n s)$. It also showed no preferred rotation $(\mathrm{RT}=.04 ; \mathrm{MT}=.03$; VT $=.18)$. Browne's (1992) criterion agreed perfectly with the exploratory criteria that the IIG showed constant radius but unequally spaced octants $(\mathrm{RMSEA}=.077$; GFI = .965; AGFI = .926). 
TABLE 3

Summary of Tests of Model Fit Using Browne's Circumplex Criterion

\begin{tabular}{|c|c|c|c|c|c|c|c|c|c|c|}
\hline \multirow[b]{2}{*}{ Sample } & \multirow[b]{2}{*}{$N$} & \multicolumn{2}{|c|}{ Model } & \multicolumn{5}{|c|}{ Goodness-of-Fit Measures } & \multirow[b]{2}{*}{$d f$} & \multirow[b]{2}{*}{$P$} \\
\hline & & Radius & Spacing & $M L D F$ & $\chi^{2}$ & RMSEA & $G F I$ & $A G F I$ & & \\
\hline \multirow[t]{4}{*}{ ICL Sample ${ }^{a}$} & \multirow[t]{4}{*}{763} & Equal & Equal & .516 & 393.19 & .142 & .882 & .823 & 24 & 12 \\
\hline & & Unequal & Equal & .485 & 369.40 & .165 & .890 & .768 & 17 & 19 \\
\hline & & Equal & Unequal & .128 & 97.66 & .079 & .970 & .936 & 17 & 19 \\
\hline & & Unequal & Unequal & .100 & 76.32 & .093 & .976 & .913 & 10 & 26 \\
\hline \multirow[t]{4}{*}{ IAS Sample $1^{\mathrm{b}}$} & \multirow[t]{4}{*}{716} & Equal & Equal & .671 & 479.91 & .163 & .857 & .785 & 24 & 12 \\
\hline & & Unequal & Equal & .453 & 323.91 & .159 & .903 & .794 & 7 & 19 \\
\hline & & Equal & Unequal & .233 & 166.81 & .111 & .949 & .891 & 17 & 19 \\
\hline & & Unequal & Unequal & .134 & 96.05 & .110 & .967 & .882 & 10 & 26 \\
\hline \multirow[t]{4}{*}{ IAS Sample $2^{\mathrm{c}}$} & \multirow[t]{4}{*}{187} & Equal & Equal & .486 & 90.43 & .122 & .896 & .844 & 24 & 12 \\
\hline & & Unequal & Equal & .202 & 37.65 & .081 & .955 & .905 & 17 & 19 \\
\hline & & Equal & Unequal & .255 & 47.41 & .098 & .970 & .936 & 17 & 19 \\
\hline & & Unequal & Unequal & .045 & 8.34 & .000 & .989 & .960 & 10 & 26 \\
\hline \multirow[t]{4}{*}{ IAS-R Sample ${ }^{\mathrm{d}}$} & \multirow[t]{4}{*}{474} & Equal & Equal & .536 & 253.63 & .142 & .884 & .825 & 24 & 12 \\
\hline & & Unequal & Equal & .434 & 205.14 & .153 & .905 & .798 & 17 & 19 \\
\hline & & Equal & Unequal & .217 & 102.60 & .103 & .947 & .887 & 17 & 19 \\
\hline & & Unequal & Unequal & .119 & 56.43 & .099 & .971 & .895 & 10 & 26 \\
\hline \multirow[t]{4}{*}{ IIP-C Sample $1^{\mathrm{b}}$} & \multirow[t]{4}{*}{616} & Equal & Equal & .337 & 207.45 & .111 & .923 & .885 & 24 & 12 \\
\hline & & Unequal & Equal & .392 & 124.30 & .141 & .913 & .815 & 17 & 19 \\
\hline & & Equal & Unequal & .123 & 75.88 & .075 & .971 & .938 & 17 & 19 \\
\hline & & Unequal & Unequal & .058 & 35.51 & .064 & .986 & .950 & 10 & 26 \\
\hline \multirow[t]{4}{*}{ IIP-C Sample $2^{\mathrm{d}}$} & \multirow[t]{4}{*}{1,381} & Equal & Equal & .222 & 306.97 & .092 & .945 & .917 & 24 & 12 \\
\hline & & Unequal & Equal & .151 & 208.61 & .090 & .963 & .922 & 17 & 19 \\
\hline & & Equal & Unequal & .090 & 123.61 & .067 & .978 & .954 & 17 & 19 \\
\hline & & Unequal & Unequal & .067 & 91.82 & .077 & .978 & .922 & 10 & 26 \\
\hline \multirow[t]{4}{*}{ IIG Sample } & \multirow[t]{4}{*}{318} & Equal & Equal & .486 & 154.10 & .131 & .899 & .849 & 24 & 12 \\
\hline & & Unequal & Equal & .392 & 124.30 & .141 & .913 & .815 & 17 & 19 \\
\hline & & Equal & Unequal & .154 & 48.80 & .077 & .965 & .926 & 17 & 19 \\
\hline & & Unequal & Unequal & .060 & 19.02 & .053 & .985 & .947 & 10 & 26 \\
\hline
\end{tabular}

Note. $\mathrm{MLDF}=$ maximum likelihood discrepancy function; RMSEA = root mean square error of approximation; $\mathrm{GFI}=$ goodness-of-fit index; $\mathrm{AGFI}=$ adjusted goodness-of-fit index; $d f=$ degrees of freedom; $\mathrm{P}=$ parameters; ICL = Interpersonal Checklist; IAS = Interpersonal Adjectives Scales; IAS-R = Revised IAS; IIP-C = Inventory of Interpersonal Problems Circumplex Scales, IIG $=$ Inventory of Interpersonal Goals. GFI = 8/ $(8+2 \times$ generalized least squares discrepancy function). AGFI $=1-(((8 \times(8+1)) /(2 \times d f)) \times(1-\mathrm{GFI}))$.

${ }^{a}$ Widowed or divorced. ${ }^{b}$ Northwestern University. ${ }^{\mathrm{c}}$ University of Oregon. ${ }^{\mathrm{d}}$ University of Wisconsin-Parkside. 


\section{DISCUSSION}

The high calling of interpersonal diagnosis of personality (Leary, 1957), which began in the 1950s, continues alive and well today. The importance of circumplex hypotheses in the interpersonal domain has led to the creation of several instruments designed as circular representations of such constructs as interpersonal traits, problems, and goals. Yet the claim of circumplex structure could not be substantiated in the absence of criteria of demonstrated effectiveness, and it has frequently been addressed using the rather unsystematic eyeball test.

The main interest of psychometric criteria for circumplex structure, once they are shown effective, is in applying them to real data. The interpersonal domain provides an ideal field for the application of such criteria. Multiple data sets on interpersonal circle measures developed from 1955 to 1997 were analyzed with respect to their circumplex properties. Without exception, the leading interpersonal measures were found by the exploratory criteria to be equal-axes circles with circumplex structure. From the perspective of interpersonal assessment, the results of this study of circumplex structure are very encouraging. Particularly encouraging is the convergence of different, uncorrelated exploratory criteria (such as Gap Test and RT) on the same conclusion.

Some differences between results from the exploratory criteria and Browne's (1992) criterion emerged. In some cases, Browne's criterion appeared more stringent than the exploratory criteria. In other cases, there was complete agreement between Browne's criterion and the exploratory criteria. It appears that Browne's criterion is fairly similar to the Fisher Test in its assessment of equal axes, is more stringent than the Gap Test in its assessment of equal spacing, and does not index absence of preferred rotation at all. These differences may suggest a hierarchical approach in which a test such as the Gap Test is applied first as a rough estimate of equal spacing, followed by Browne's criterion as a more stringent estimate.

The new exploratory criteria we presented in this article can be considered second- or third-generation methods for assessing circumplex structure. Most previous circumplex criteria have indexed the requirement of equal spacing. Wiggins et al. (1981) introduced a criterion that requires accounting for both equal spacing and a fair amount of variance. The latter amounts to a requirement that variables fall within the two-dimensional space under consideration, which would be indicated in a factor analysis by reasonably large vector lengths or communalities on the two circumplex factors. Whereas our analyses assumed the importance of equal spacing, another important assumption is that two factors should capture much of the variance in a group of variables thought to form a circumplex. Gurtman's (1997) uniform probability criterion, which also requires equal spacing, can be tested using Rao's Gap Test (Upton \& Fingleton, 1989). Acton (1999) tested a criterion explicitly based on Rao's Gap Test called the Gap Difference (GDIFF) Test. Whereas the Gap Test (applied above) is based on the difference 
between pairs of observed variable locations, the GDIFF Test is based on the difference between observed and ideal variable locations. Simulations showed that the Gap Test was effective at detecting circumplex structure, but the GDIFF Test was not (Acton, 1999).

Although previous research on the new exploratory criteria (Acton, 1999) yielded promising results, further research on these criteria seems warranted. If future psychometric studies are not inconsistent with the effectiveness of the new criteria, applications to models such as the affective circumplex (Russell, 1980) and the abridged Big-Five circumplex (Hofstee et al., 1992) could help to establish circumplex structure in their respective domains. Indeed, applications to other measures within the interpersonal domain, such as the Circumplex Scales of Interpersonal Values (Locke, 2000) and the octant scale Impact Message Inventory (Schmidt, Wagner, \& Kiesler, 1999) would also appear fruitful.

The results of these analyses help to establish circumplex structure in the interpersonal domain. It appears that things interpersonal are not simple exemplars of unrelated subdomains but are interwoven elements of a more complex, higher order field. Any adequate description of variables measuring the breadth of interpersonal relationships will include subtle gradations along a circular continuum.

\section{ACKNOWLEDGMENTS}

Work on this article was supported in part by a Graduate Research Fellowship from the National Science Foundation to G. Scott Acton. This article is based on G. Scott Acton's doctoral dissertation at Northwestern University. We are grateful to J. Michael Bailey, Kevin L. Delucchi, Michael B. Gurtman, and Richard E. Zinbarg for helpful comments on earlier versions of this article.

\section{REFERENCES}

Acton, G. S. (1998). Classification of psychopathology: The nature of language. The Journal of Mind and Behavior, 19, 243-256.

Acton, G. S. (1999). Interpersonal theory and circumplex structure. Unpublished doctoral disseration, Northwestern University, Evanston, IL.

Alden, L. E., Wiggins, J. S., \& Pincus, A. L. (1990). Construction of circumplex scales for the Inventory of Interpersonal Problems. Journal of Personality Assessment, 55, 521-536.

Bartholomew, K., \& Horowitz, L. M. (1991). Attachment styles among young adults: A test of a fourcategory model. Journal of Personality and Social Psychology, 61, 226-244.

Blas, L. D., \& Forzi, M. (1998). The circumplex model for interpersonal trait adjectives in Italian. Personality and Individual Differences, 24, 47-57.

Browne, M. W. (1992). Circumplex models for correlation matrices. Psychometrika, 57, 469-497.

Browne, M. W., \& Cudeck, R. (1992). Alternative ways of assessing model fit. Sociological Methods and Research, 21, 230-258. 
Buss, D. M., \& Barnes, M. (1986). Preferences in mate selection. Journal of Personality and Social Psychology, 50, 559-570.

Buss, D. M., \& Chiodo, L. M. (1991). Narcissistic acts in everyday life. Journal of Personality, 59, 179-215.

Buss, D. M., Gomes, M., Higgins, D. S., \& Lauterbach, K. (1987). Tactics of manipulation. Journal of Personality and Social Psychology, 52, 1219-1229.

Davies-Osterkamp, S., Strauss, B. M., \& Schmitz, N. (1996). Interpersonal problems as predictors of symptom related treatment outcome in longterm psychotherapy. Psychotherapy Research, 6, 164-176.

Dryer, D. C., \& Horowitz, L. M. (1997). When do opposites attract? Interpersonal complementarity versus similarity. Journal of Personality and Social Psychology, 72, 592-603.

Fisher, G. A. (1997). Theoretical and methodological elaborations of the circumplex model of personality traits and emotions. In R. Plutchik \& H. R. Conte (Eds.), Circumplex models of personality and emotions (pp. 245-269). Washington, DC: American Psychological Association.

Foa, U. G., \& Foa, E. B. (1974). Societal structures of the mind. Springfield, IL: Thomas.

Freedman, M. B., Leary, T. F., Ossorio, A. G., \& Coffey, H. S. (1951). The interpersonal dimension of personality. Journal of Personality, 20, 143-161.

Gaines, S. O., Jr., Panter, A. T., Lyde, M. D., Steers, W. N., Rusbult, C. E., Cox, C. L., \& Wexler, M. O. (1997). Evaluating the circumplexity of interpersonal traits and the manifestation of interpersonal traits in interpersonal trust. Journal of Personality and Social Psychology, 73, 610-623.

Gifford, R., \& O'Connor, B. (1987). The interpersonal circumplex as a behavioral map. Journal of Personality and Social Psychology, 52, 1019-1026.

Goldberg, L. R. (1982). From ace to zombie: Some explorations in the language of personality. In C. D. Spielberger \& J. N. Butcher (Eds.), Advances in personality assessment (Vol. 1, pp. 203-234). Hillsdale, NJ: Lawrence Erlbaum Associates, Inc.

Gurtman, M. B. (1992a). Construct validity of interpersonal personality measures: The interpersonal circumplex as a nomological net. Journal of Personality and Social Psychology, 63, 105-118.

Gurtman, M. B. (1992b). Trust, distrust, and interpersonal problems: A circumplex analysis. Journal of Personality and Social Psychology, 62, 989-1002.

Gurtman, M. B. (1993). Constructing personality tests to meet a structural criterion: Application of the interpersonal circumplex. Journal of Personality, 61, 237-263.

Gurtman, M. B. (1995). Personality structure and interpersonal problems: A theoretically guided item analysis of the Inventory of Interpersonal Problems. Assessment, 2, 343-361.

Gurtman, M. B. (1996). Interpersonal problems and the psychotherapy context: The construct validity of the Inventory of Interpersonal Problems. Psychological Assessment, 8, 241-255.

Gurtman, M. B. (1997). Studying personality traits: The circular way. In R. Plutchik \& H. R. Conte (Eds.), Circumplex models of personality and emotions (pp. 81-102). Washington, DC: American Psychological Association.

Gurtman, M. B., \& Balakrishnan, J. D. (1998). Circular measurement redux: The analysis and interpretation of interpersonal circle profiles. Clinical Psychology: Science and Practice, 5, 344-360.

Gurtman, M. B., \& Pincus, A. L. (2000). Interpersonal Adjective Scales: Confirmation of circumplex structure from multiple perspectives. Personality and Social Psychology Bulletin, 26, 374-384.

Guttman, L. (1954). A new approach to factor analysis: The radex. In P. F. Lazarsfeld (Ed.), Mathematical thinking in the social sciences (pp. 258-348). Glencoe, IL: Free Press.

Haslam, N., \& Gurtman, M. B. (1999). Detecting complex patterns in interpersonal profiles. British Journal of Medical Psychology, 72, 23-32.

Hersh, H. M., \& Caramazza, A. (1976). A fuzzy set approach to modifiers and vagueness in natural language. Journal of Experimental Psychology: General, 105, 251-276.

Hofstee, W. K. B., de Raad, B., \& Goldberg, L. R. (1992). Integration of the Big Five and circumplex approaches to trait structure. Journal of Personality and Social Psychology, 63, 146-163. 
Horowitz, L. M. (1979). On the cognitive structure of interpersonal problems treated in psychotherapy. Journal of Consulting and Clinical Psychology, 47, 5-15.

Horowitz, L. M., Dryer, D. C., \& Krasnoperova, E. N. (1997). The circumplex structure of interpersonal problems. In R. Plutchik \& H. R. Conte (Eds.), Circumplex models of personality and emotions (pp. 347-384). Washington, DC: American Psychological Association.

Horowitz, L. M., \& Malle, B. F. (1993). Fuzzy concepts in psychotherapy research. Psychotherapy Research, 3, 131-148.

Horowitz, L. M., Rosenberg, S. E., Baer, B. A., Ureño, G., \& Villaseñor, V. S. (1988). The Inventory of Interpersonal Problems: Psychometric properties and clinical applications. Journal of Consulting and Clinical Psychology, 56, 885-895.

Horowitz, L. M., Rosenberg, S. E., \& Bartholomew, K. (1993). Interpersonal problems, attachment styles, and outcome in brief dynamic psychotherapy. Journal of Consulting and Clinical Psychology, 61, 549-560.

Jöreskog, K. G., \& Sörbom, D. (1986). Analysis of linear structural relationships by the method of maximum likelihood. Mooresville, IN: Scientific Software.

Kiesler, D. J. (1983). The 1982 interpersonal circle: A taxonomy for complementarity in human transactions. Psychological Review, 90, 185-214.

LaForge, R., \& Suczek, R. F. (1955). The interpersonal dimension of personality: III. An interpersonal checklist. Journal of Personality, 24, 94-112.

Leary, T. (1957). Interpersonal diagnosis of personality: A functional theory and methodology for personality evaluation. New York: Ronald Press.

Locke, K. D. (2000). Circumplex Scales of Interpersonal Values: Reliability, validity, and applicability to interpersonal problems and personality disorders. Journal of Personality Assessment, 75, 249-267.

Maiti, S. S., \& Mukherjee, B. N. (1990). A note on the distributional properties of the Jöreskog-Sörbom fit indices. Psychometrika, 55, 721-726.

Maling, M. S., Gurtman, M. B., \& Howard, K. I. (1995). The response of interpersonal problems to varying doses of psychotherapy. Psychotherapy Research, 5, 63-75.

McCormick, C. C., \& Goldberg, L. R. (1997). Two at a time is better than one at a time: Exploiting the horizontal aspects of factor representations. In R. Plutchik \& H. R. Conte (Eds.), Circumplex models of personality and emotions (pp. 103-132). Washington, DC: American Psychological Association.

McCormick, C. C., \& Kavanagh, J. A. (1981). Scaling Interpersonal Checklist items to a circular model. Applied Psychological Measurement, 5, 421-447.

McCrae, R. R., \& Costa, P. T. (1989). The structure of interpersonal traits: Wiggins' circumplex and the five-factor model. Journal of Personality and Social Psychology, 56, 586-595.

Muran, J. C., Segal, Z. V., Samstag, L. W., \& Crawford, C. E. (1994). Patient pretreatment interpersonal problems and therapeutic alliance in short-term cognitive therapy. Journal of Consulting and Clinical Psychology, 62, 185-190.

Paddock, J. R., \& Nowicki, S., Jr. (1986). An examination of the Leary circumplex through the Interpersonal Check List. Journal of Research in Personality, 20, 107-144.

Pincus, A. L., Gurtman, M. B., \& Ruiz, M. A. (1998). Structural analysis of social behavior (SASB): Circumplex analyses and structural relations with the interpersonal circle and the five-factor model of personality. Journal of Personality and Social Psychology, 74, 1629-1645.

Revelle, W., \& Rocklin, T. (1979). Very simple structure: An alternative procedure for estimating the optimal number of interpretable factors. Multivariate Behavioral Research, 14, 403-414.

Rosén, A. S. (1992). The circle as a model for the interpersonal domain of Swedish trait terms. European Journal of Personality, 6, 283-299.

Russell, J. A. (1980). A circumplex model of affect. Journal of Personality and Social Psychology, 39, 1161-1178. 
Saucier, G. (1992). Benchmarks: Integrating affective and interpersonal circles with the Big-Five personality factors. Journal of Personality and Social Psychology, 62, 1025-1035.

Schmidt, J. A., Wagner, C. C., \& Kiesler, D. J. (1999). Psychometric and circumplex properties of the octant scale Impact Message Inventory (IMI-C): A structural evaluation. Journal of Counseling Psychology, 46, 325-334.

Schumacker, R. E., \& Lomax, R. G. (1996). A beginner's guide to structural equation modeling. Mahwah, NJ: Lawrence Erlbaum Associates, Inc.

Sullivan, H. S. (1953). The interpersonal theory of psychiatry. New York: Norton.

Taulbee, E. S., \& Clark, T. L. (1982). A comprehensive, annotated bibliography of selected psychological tests: Interpersonal Check List, MMPI, Short Form, The Blacky Pictures. Troy, NY: Whitston.

Thurstone, L. L. (1947). Multiple factor analysis. Chicago: University of Chicago Press.

Tracey, T. J. G., Rounds, J., \& Gurtman, M. (1996). Examination of the general factor with the interpersonal circumplex structure: Application to the Inventory of Interpersonal Problems. Multivariate Behavioral Research, 31, 441-466.

Trapnell, P. D., \& Wiggins, J. S. (1990). Extension of the Interpersonal Adjective Scales to include the Big Five dimensions of personality. Journal of Personality and Social Psychology, 59, 781-790.

Upton, G. J. G., \& Fingleton, B. (1989). Spatial data analysis by example: Vol. 2. Categorical and directional data. New York: Wiley.

Weinryb, R. M., Gustavsson, J. P., Hellström, C., Andersson, E., Broberg, A., \& Rylander, G. (1996). Interpersonal problems and personality characteristics: Psychometric studies of the Swedish version of the IIP. Personality and Individual Differences, 20, 13-23.

Whiteman, M. C., Bedford, A., Grant, E., Fowkes, F. G. R., \& Deary, I. J. (2001). The five-factor model (NEO-FFI) and the Personality Deviance Scales-Revised (PDS-R): Going around in interpersonal circles. Personality and Individual Differences, 31, 259-267.

Wiggins, J. S. (1979). A psychological taxonomy of trait-descriptive terms: The interpersonal domain. Journal of Personality and Social Psychology, 37, 395-412.

Wiggins, J. S., \& Broughton, R. (1985). The interpersonal circle: A structural model for the integration of personality research. In R. Hogan \& W. H. Jones (Eds.), Perspectives in personality (Vol. 1, pp. $1-47)$. Greenwich, CT: JAI.

Wiggins, J. S., \& Broughton, R. (1991). A geometric taxonomy of personality scales. European Journal of Personality, 5, 343-365.

Wiggins, J. S., Phillips, N., \& Trapnell, P. (1989). Circular reasoning about interpersonal behavior: Evidence concerning some untested assumptions underlying diagnostic classification. Journal of Personality and Social Psychology, 56, 296-305.

Wiggins, J. S., Steiger, J. H., \& Gaelick, L. (1981). Evaluating circumplexity in personality data. Multivariate Behavioral Research, 16, 263-289.

Wiggins, J. S., Trapnell, P., \& Phillips, N. (1988). Psychometric and geometric characteristics of the Revised Interpersonal Adjective Scales (IAS-R). Multivariate Behavioral Research, 23, 517-530.

\author{
G. Scott Acton \\ Langley Porter Psychiatric Institute \\ University of California, San Francisco \\ Box 0984-TRC \\ 401 Parnassus Avenue \\ San Francisco, CA 94143-0984 \\ E-mail: acton@itsa.ucsf.edu
}

Received March 21, 2002 